\title{
The Effects of Preventive Home Visits on Older People's Use of Health Care and Social Services and Related Costs
}

\section{Liimatta, Heini A}

2020-08

Liimatta , H A , Lampela , P , Kautiainen , H , Laitinen-Parkkonen , P \& Pitkälä , K H 2020 , '

The Effects of Preventive Home Visits on Older People's Use of Health Care and Social

Services and Related Costs ', Journals of Gerontology. Series A: Biological Sciences and

Medical Sciences , vol. 75 , no. 8 , pp. 1586-1593 . https://doi.org/10.1093/gerona/glz139

http://hdl.handle.net/10138/331934

https://doi.org/10.1093/gerona/glz139

acceptedVersion

Downloaded from Helda, University of Helsinki institutional repository.

This is an electronic reprint of the original article.

This reprint may differ from the original in pagination and typographic detail.

Please cite the original version. 
The Effects of Preventive Home Visits on Older People's Use of Health Care and Social Services and Related Costs

Heini Liimatta, M.D. ${ }^{1,2 *}$, Pekka Lampela, M.D., Ph.D. ${ }^{3}$, Hannu Kautiainen, B.A., Biostatistician ${ }^{2,5}$, Pirjo Laitinen-Parkkonen, M.D., Ph.D., Adjunct Professor ${ }^{4}$, and Kaisu H. Pitkala, M.D., Ph.D., Professor ${ }^{2,5}$

${ }^{1}$ Hyvinkää City Health Center, Sandelininkatu 1, 05800 Hyvinkää, Finland

${ }^{2}$ University of Helsinki, Department of General Practice and Primary Health Care

${ }^{3}$ Hyvinkää City Health Center, Sairaalankatu 3, 05800 Hyvinkää, Finland

${ }^{4}$ Keski-Uusimaa Joint Municipality Authority for Health Care and Social Services

${ }^{5}$ Helsinki University Hospital, Unit of Primary Health Care

Corresponding author:

Heini Liimatta, Hyvinkää City Health Center, Sandelininkatu 1, 05800 Hyvinkää, Finland, Telephone: +358 40755 4183, heini.liimatta@gmail.com, heini.liimatta@keusote.fi, ORCiD ID 0000-0002-53916018

\section{Disclosure of interest}

The authors declare that they have no conflicts of interest.

(C) The Author(s) 2019. Published by Oxford University Press on behalf of The Gerontological Society of America. All rights reserved. For permissions, please e-mail: journals.permissions@oup.com. 


\begin{abstract}
Background

We use data from a randomized controlled trial on preventive home visits (PHVs) exploring effectiveness on health-related quality of life (HRQoL). In this article we examine the intervention's cost effectiveness and effects on quality-adjusted life years (QALYs) in older home-dwelling adults.
\end{abstract}

\title{
Methods
}

There were 422 independently home-dwelling participants in the randomized, controlled trial, all aged over 75 years, with equal numbers in the control and intervention groups. The intervention took place in a municipality in Finland and consisted of multiprofessional PHVs. We gathered the data on healthcare and social services use from central registers and medical records during one year before the intervention and two years after the intervention. We analyzed the total health-care and social services use and costs per person years and the difference in change in HRQoL as measured using the 15D measure. We calculated QALYs and incremental cost-effectiveness ratios (ICERs).

\section{Results}

There was no significant difference in baseline use of services or in the total use and costs of healthcare and social services during the two-year follow-up between the two groups. In the intervention group HRQoL declined significantly more slowly compared to the control group (-0.015), but there was no significant difference in QALYs gained between the groups. The cost-effectiveness plane showed $60 \%$ of ICERs lying in the dominant quadrant, representing additional effects with lower costs.

\section{Conclusions}

This multiprofessional PHV intervention appears to have positive effects on HRQoL without accruing additional costs.

Keywords : Preventative Health Care; Health Services; Geriatric Assessment; Primary Care; Cost Effectiveness

The clinical trial registration number: ACTRN12616001411437 


\section{Introduction}

Aging populations are a modern demographic trend in many societies. This phenomenon has wideranging implications for a society and its citizens, including implications for expenditures on health care and social services. (1). The use of preventive home visits (PHVs) has been studied as a means to support the well-being of older adults and to postpone the onset of disabilities (2-4). Interventions designed to reduce disability might result in lower costs for health care and social services if they have the potential to reduce hospitalizations and institutionalizations $(2,5)$. This reasoning has led to preventive measures, including PHVs, to be included as part of national health care policy in some countries, such as Denmark, the U.K., and Australia (5).

Although PHVs have been studied for decades, there is little evidence regarding their cost effectiveness $(3,5)$. Some studies have suggested that PHV interventions decrease hospitalizations and nursing home admissions, and that they shorten hospital stays; thus, they may have positive effects on health care costs (6-9). However, the evidence has been contradictory in other studies $(3,10)$. Our earlier review suggested that some PHV programs might yield favorable results in well-being, functioning, and mortality, and that they are cost neutral (3).

Older people reported social aspects and well-being important when considering PHV intervention contents and outcomes (11). However, research on well-being and health-related quality of life (HRQoL) and cost effectiveness related to it has lagged behind (12). The few existing studies have yielded varying results concerning both HRQoL and costs $(2,5,12)$. A recent meta-analysis found the proactive care interventions targeted to older people are unlikely to be cost-effective after one year, but the heterogeneity of the interventions and evaluation of the effects on the group level might have diluted the results (13). However, both older people and professionals have evaluated proactive multidisciplinary care positively, and it warrants for further research $(11,13)$.

We have previously reported on a randomized, controlled trial (RCT) on the effectiveness of multiprofessional PHVs on HRQoL of older home-dwelling individuals (age 75+). The participants received no regular home help or care and the trial was conducted in Finland (14). Our study indicated the intervention might slow down the decline in the HRQoL of older adults. We report here on an analysis of the effects of the intervention on the participants' use of health-care and social services and related costs, as well as an analysis of the cost effectiveness of the intervention.

\section{Methods}

\subsection{Design}

We performed a randomized, controlled, single-center trial in Finland, including a two-year follow-up, focusing on the effects of PHVs on HRQoL and on the use of and costs related to the use of health care and social services. We have described the methods used, the baseline findings, the feasibility of the intervention, and the primary clinical outcomes in detail in earlier papers (14-15). We provided oral and written information to all participants and participants provided their written informed consent. The Ethics Committee of the Helsinki University Central Hospital provided ethics approval for our study. The study protocol was registered with the Australian New Zealand Clinical Trials Registry (ANZCTR). 


\subsection{Participants and setting}

We recruited 422 participants to take part the study in 2013. A letter about the study was sent to all 2,692 residents aged 75 years or older in Hyvinkää, which is a mid-size Finnish town with 46,600 inhabitants. We included in the pool of potential participants all those who were 75 years old or older, home dwelling, not receiving home help or nursing services, living permanently in the Hyvinkää area, and Finnish speaking. We recruited from those who returned a letter showing an interest in participating in the study $(n=968)$ the first consecutive 422 individuals who met the inclusion criteria and who provided their informed consent (Figure 1). We used computer-generated random numbers from Research Randomizer (16), seeded by the computer's clock, after the baseline assessment to randomize participants into the intervention $(n=211)$ and control $(n=211)$ groups. Two randomizations were performed as 62 spouses were randomized together to avoid dilution of the intervention effect.

\subsection{Measures and study procedures}

Data were collected using the same postal survey at baseline and at one- and two-year follow-up time points. Baseline items included social demographics (gender, age, marital status, and education), current weight and height, current medications, use of assistive devices, diagnoses, health habits, and risk factors (smoking, use of alcohol, exercise habits, and falls during the past six months). Data on the use and costs of health-care and social services for one year before the intervention (baseline) and at the two-year follow-up were collected from health-care information systems and databases. We performed the assessments and interventions in 2013 and 2014. To explore the cost effectiveness of the intervention we compared the groups in respect to their health-care and social services use and the related costs during the two-year follow-up after the intervention.

We measured the utilization and costs of health-care and social services in detail from central registers and medical records for one year before the intervention and for two years after the initial home visit or until the participant's death. The use of hospital services and community care services in Finland is reliably recorded in medical records and central registers. All visits to primary care physicians and nurses, visits with other healthcare specialists (like physiotherapists, occupational therapists, nutritionists), home-care visits, time spent at day centers, days spent in institutions (various hospitals, nursing homes, or long-term care hospitals), and visits to specialist doctors during the two-year follow-up were retrieved from central registers, from patient medical records in their primary care and area hospitals, and from social care registers. These data were collected from Population Register Centre, Kanta Patient Data Repository, Pegasos patient information system for medical and social services records of the municipality and Navitas reference database for community care services received outside Hyvinkää municipality and hospital services. Health-care and social service costs were determined using mean unit costs for Finland for year 2011 reported by the Finnish National Institute for Health and Welfare (17), with an appropriate correction added for the inflation rate based on the official cost-of-living index. Total costs were calculated by multiplying the number of health and social care services utilization units with cost prices of each unit. Costs are presented in Euros $(€)$. Intervention costs were calculated according to the unit costs for each of the three home visits.

The primary outcome measure, as reported in our earlier papers, was HRQoL as assessed using the measurement tool referred to as the $15 \mathrm{D}$. As a generic assessment measurement, this 15 -item questionnaire can be used as a profile measurement or as a single index. The domains of assessment of the $15 \mathrm{D}$ consist of mobility, vision, hearing, breathing, sleeping, eating, speech, elimination, usual 
activities, mental function, discomfort and symptoms, depression, distress, vitality, and sexual activity. In the trial we used the 15D data as an index score which varied between 0 (poorest HRQoL) and 1 (excellent HRQoL). We sent the 15D as a postal questionnaire since the 15D can be independently filled out. The questionnaire was sent at baseline and at one- and two-year follow-up time points, and the participants were asked to answer according to their current health status.

Mortality data were retrieved from central registers. The Finnish register system's follow-up on mortality is $100 \%$ complete.

\subsection{Intervention}

Briefly, participants in the intervention group received three PHVs in which a thorough comprehensive geriatric assessment (18-19) was conducted using validated measurement tools. Recommendations and actions were taken based on the assessment results. The home visits were performed by specially trained nurses, by a physiotherapist, and by a social worker, in this order, during a six-to nine-month period. The professionals performing the home visits were thoroughly trained. The control group received standard care, and, thus, all health and social care services offered by the municipality were available to them when needed. In addition, they received and answered the same postal questionnaires as the intervention group. We have described the intervention in more detail earlier (14-15).

The first part of the assessment was performed by the nurse, who measured the participants' blood pressure and blood glucose levels and conducted a thorough assessment of their health and functioning using a battery of validated measures (interRAI Home Care Assessment System [20], Mini-Mental State Examination [21], Mini Nutritional Assessment [22], Barthel scale [23], The 15-item Geriatric Depression Scale [24], and Instrumental Activities of Daily Living [IADL] [25]).

The physiotherapist assessed home safety and barriers to mobility using validated tests (Falls Risk for Older People - Community setting screen [26]), assessed the need for aids, measured hand grip strength (Jamar [27]) and performed a chair-stand test (CS-5 [28]).

The social worker assessed social functioning, activities of daily living (ADL, IADL [20,25]), and service needs.

In addition to administering the assessment tools, the nurse formulated individualized plans with the participants for further actions and made a referral to a GP if necessary. The physiotherapist compiled individualized exercise plans, gave information on exercise groups available, and made a referral for physiotherapy sessions if necessary, and the social worker provided information on benefits available to the participants and provided contact information for a service provider. The physiotherapist and social worker filled in instructions on the information card when needed.

\section{$2.5 \quad$ Statistical analyses}

Sample size was estimated based on the 15D, our primary outcome measure. The calculation was based on a change of 0.03 points in the 15D index score (17). In prior studies the standard deviation in the 15D score was 0.15 (29). Based on the calculation, we would need a minimum sample size of 196 study participants per study arm for a Type 1 Error of $5 \%$ and a power of $80 \%$. All randomized participants were included in the analysis of use and costs of health care and social services (intention to treat). 
Statistical comparisons between the groups were made using the t-test, the bootstrap type t-test, or the chi-square test when appropriate. Mean changes in the 15D score were assessed using the mixedmodel repeated measure methods with treatment, visit, and treatment-visit interaction as fixed effects; the model included the baseline score as a covariate. Comparisons between the groups for costs were made using the bootstrap type t-test and generalized Hodges-Lehmann median differences.

Means ratio with a $95 \%$ confidence interval (CI) for cost was modeled using generalized linear models with a log link function and a gaussian distribution. Bias-corrected bootstrapping $(10,000$ replications) was used to obtain the CIs for the means because of the skewed distribution of the use and costs of health-care and social services. Outcomes for the cost-utility analysis are expressed in terms of generic quality-adjusted life years (QALYs), measured using the 15D. All participants who completed the baseline and at least one follow-up assessment were included for the 15D and QALY analysis. For a health economic evaluation, we performed a cost-utility analysis in relation to QALY derived from the area under the curve calculation for the 15D score from baseline to last follow up. Data for the cost-utility analysis were collected at the baseline, at 12 months, and at 24 months. We evaluated the incremental cost-effectiveness ratio (ICER) as being the ratio of the mean difference in cost to the mean difference in effect. Missing values for follow-up observations of 15D (intervention $n$ $=22$ and control $\mathrm{n}=26$ ) were imputed using multiple imputation by chained equations (30). The imputation model included all analysis variables (Table 1). Multiple data sets $(\mathrm{N}=10)$ were generated to account for the uncertainty in imputed data. All statistical analyses were performed using Stata statistical software version 15.1 (StataCorp, College Station, Texas, USA).

\section{Results}

We included 422 participants in the study, randomized equally into the intervention group or the control group. The baseline characteristics were well balanced between the randomized groups. The mean age of the participants was 81 years and $65 \%$ were females. The groups were similar with respect to years of education and comorbidities, and there was no significant difference in HRQoL according to $15 \mathrm{D}$ scores at baseline. There were no differences between the intervention and control group in terms of health- and social-care use during the year previous to the intervention (Table 1).

\subsection{Use and Costs of Health and Social Services}

Table 2 shows the mean use and costs of health care and social services per person years for the intervention and control groups during the 24-month follow-up. Mean and median total cost per person year for the 24-month follow-up was mean 6929€ (SE 846) and median 1848€ (IQR: 837 , 7341 ) in the intervention group and mean $8277 €$ (SE 1089) and median $2485 €$ (IQR: 1049, 7231) in the control group. The difference between the intervention and control groups was not significant (mean difference $-1349 €[-4119 €$ to $1172 €]$ and median difference $-258 €[-711 €$ to $157 €]$ ). The intervention costs were $382 €$ per participant. Including the intervention costs in the total costs for the intervention group did not change the findings, with the mean total costs per person at 24-month follow-up being $7310 €$ (SE 849) for the intervention group. The mean difference between groups when including intervention costs was $-967 €$ (-3766 to 1633) (mean ratio 0.84 [0.55 to 1.13$]$ ).

In the intervention group HRQoL declined significantly more slowly compared to in the control group (Table 3). However, there was no significant difference in QALYs gained. The mean for QALYs was 
0.819 (SD 0.112) in the intervention group whereas the respective figure in the control group was 0.812 (SD 0.114). The difference in QALYs was -0.007 (95\% CI -0.029 to $0.015 ; \mathrm{p}=0.52$ ) and after performing an imputation -0.005 (95\% CI -0.035 to $0.022 ; \mathrm{p}=0.48$ ).

The cost-effectiveness plane for the cost-utility analysis bootstrap analysis for QALYs (Figure 2) shows that $60 \%$ of the ICERs lie in the dominant ("south east") quadrant that represents the probability of the intervention having more effect and lower costs compared with usual care. Thus, we can conclude that the intervention retained HRQoL cost-neutrally.

\section{Discussion}

In this analysis, based on data from an RCT, we explored the cost effectiveness of multiprofessional PHVs that included a comprehensive geriatric assessment for older adults. We found no significant difference between the intervention group and the control group in terms of use and costs of health and social services or in the QALYs gained. Yet, HRQoL declined significantly more slowly for the intervention group during the first year of follow up and 60\% of ICERs lay in the dominant quadrant, suggesting a possibility for the intervention having a positive effect with lower costs compared to usual treatment. Thus, the favorable effects of the intervention on HRQoL as we measured it were achieved cost-neutrally.

Our trial had several strengths. It was based on an RCT with sufficient power to explore the effects of the intervention on HRQoL. Our intervention was designed to be affordable, feasible, and transferable to other contexts in primary care. It was based on comprehensive geriatric assessment (19-20) and on validated measurements, and the participants reported being mainly satisfied with the intervention (15).

We included all participants in the cost analysis (true intention-to-treat) and the dropout rate for the analysis of QALYs was low for a study targeting older people (31-32), with 88\% of the intervention group and $85 \%$ of the control group having at least two 15D measurements included in the analysis. In addition, we performed an imputation for modified intention-to-treat analysis of QALYs and the results did not differ notably from the original analysis. We had complete information of service use and costs of all participants until the time of death or end of the follow-up, as these data were retrieved from registers. We used a patient-relevant outcome measure, HRQoL assessed using the $15 \mathrm{D}$, which is well validated and has worked well with older populations in earlier studies (16,33-34). The single composite score of 15D is particularly valid for deriving QALYs gained (17). The use of health and social services in Finland is reliably recorded in medical records and central registers, yielding solid data for the evaluation of the cost effectiveness of the intervention. The intervention and control groups had comparable rates for use of services at baseline. The intervention visits and related costs were not included in the services use data collected from health-care information systems and databases. We assessed the intervention costs individually, while any additional health and social services costs incurred in the course of the intervention were included in the standard services use data kept by health-care information systems and databases. This eliminated the possibility of double counting the intervention visits or costs.

Our study had some limitations. We could not blind the participants or the professionals delivering the intervention due to the nature of the study. The data was not blinded at the time of the analysis, but we followed strictly the intention-to-treat principles. The lack of difference between the intervention and control groups in QALYs gained might be related to our study not having enough power to detect 
differences in mortality between the groups. Performing a qualitative study prior to the RCT might have made the intervention more personalized $(13,35)$. However, this protocolized intervention was feasible (15) and in its present form also easily transferable in Finnish health care system.

Furthermore, a pilot study might have reduced uncertainties in the trial design (35-36). As the participants were from the area of one municipality in Finland, the sample might be too homogenous considering generalization of the findings to other populations. Interventions which are part of complex health care services have to be considered in the context of the underlying health care system $(35,37)$.

Results on the cost effectiveness of PHVs have varied in earlier papers, and results of economic evaluations are challenging to compare as they have to be interpreted in national contexts. Overall, a small number of the studies concerning PHVs report both HRQoL outcomes and costs of health services use $(2,5,12)$. Our study did not show a significant difference between the control and intervention groups in the mean use or costs of services, which is in line with earlier findings $(2,5,38)$. Some studies have found favorable effects of PHVs on functional status or on HRQoL without increased costs, a finding that our study confirms $(2,37)$. However, other studies have reported no clear effects on either clinical outcomes or total costs $(5,12)$. Metzelthin et al. found in their study only $2 \%$ of ICERs lay in the dominant quadrant (5), compared to our finding of $60 \%$ of ICERs in the dominant quadrant. Our study might have been able to show favorable effects on HRQoL due to the satisfactory number of participants, the multiprofessional nature of the intervention and its reliance on comprehensive geriatric assessement, and the use of a primary outcome measure based on a tool that has previously been shown to be sensitive to change in older populations $(14,39)$.

There can be other reasons for the lack of effect on use and costs of services: As the distribution of services use and costs is usually distinctly positively skewed, showing a statistically significant difference between groups is difficult and requires a large number of participants in the study arms. Our sample size was calculated based on the primary outcome, HRQoL in terms of 15D index scores, and therefore it is possible that the power of our study was not large enough to show such a difference. The difference between the control and intervention groups in the change in the 15D score, although small (0.015), is considered clinically significant compared to the change found in earlier research $(12,39)$ : at the same time there was no significant difference in QALYs gained between the groups. This is likely due to several reasons. The difference in change in 15D scores was small, and the effect diluted in the second year of follow-up. We did not detect a significant difference in mortality between two groups. This explains why the QALYs of the two groups were fairly similar. The costeffectiveness plane suggests that the intervention might have favorable effects with lower costs than for standard care $(5,20)$. As there was no significant difference in mean total costs per person years, we interpret this result as the intervention having favorable effects without an increase in costs.

It is unclear if continuing the support past the initial year of intervention would have yielded additional effects on HRQoL. This should be further studied. Considering that we did not have the power to detect differences in mortality in this trial, and the effect on HRQoL diluted in the second year of follow-up, further follow-up on use and costs of health-care and social services of the participants in this trial would not likely yield more information on the cost effectiveness. When planning future studies concerning the cost effectiveness of multiprofessional PHV programs, the power needed to show differences in health-care and social services costs between groups should be considered. The increased understanding of the complexity of health care and studying complex interventions offer novel approaches for future studies on PHV interventions. 
Health care is experiencing several changes and challenges, one of which is the increase of multimorbid older people. The understanding of complex health care interventions and their research has increased during recent years. New ways of studying these interventions have been introduced in addition to conventional research methods (37). However, individually randomized trials are still seen important when they are technically and ethically applicable (35).

\subsection{Conclusions}

The multiprofessional PHV intervention showed cost-neutral favorable effects on HRQoL. We did not detect differences in total use or costs of services or in QALYs gained, but the ICER analysis suggested the intervention to be favorable and cost-effective.

\section{Funding}

This work was supported by a university-level health research grant from HYKS's area of responsibility (ERVA) [four grants for the research group between 2013 and 2016]; as well as by the Medical Officer Uulo Arhio Foundation in 2016 to H.L.; the Finnish Medical Foundation in 2016 and 2018 to H.L; the Paulo Foundation in 2018 to H.L.; and the Sohlberg Foundation in 2018 to H.L.

\section{Acknowledgements}

The authors wish to thank Janne Kasurinen, Marja-Liisa Mustonen, Kaarina Moisio, and Tarja LaitilaMphande for their work with the study subjects and data collection. All authors have materially participated in the research and article preparation. The sponsors' have not participated in the design or implementation of the research or reporting the results. 


\section{References}

1. Ince Yenilmez, M. Economic and Social Consequences of Population Aging the Dilemmas and Opportunities in the Twenty-First Century. Appl Res Qual Life. 2014;10:735. doi: 10.1007/s11482-014-9334-2

2. Fairhall N, Sherrington C, Kurrle SE et al. Economic evaluation of a multifactorial, interdisciplinary intervention versus usual care to reduce frailty in frail older people. J Am Med Dir Assoc. 2015;16:41-48. doi: 10.1016/j.jamda.2014.07.006

3. Liimatta H, Lampela P, Laitinen-Parkkonen P, Pitkala KH. Effects of preventive home visits on older people's use and costs of health care services: A systematic review. Eur Geriatr Med. 2016;7:571-580. doi: 10.1080/02813432.2019.1569372

4. Mayo-Wilson E, Grant S, Burton J, Parsons A, Underhill K, Montgomery P. Preventive home visits for mortality, morbidity, and institutionalization in older adults: a systematic review and meta-analysis. PLoS One. 2014;9:e89257. doi: 10.1371/journal.pone.0089257

5. Metzelthin SF, van Rossum E, Hendriks MR et al. Reducing disability in community-dwelling frail older people: cost-effectiveness study alongside a cluster randomised controlled trial. Age Ageing. 2015;44:390-396. doi: 10.1093/ageing/afu200

6. Frese T, Deutsch T, Keyser M, Sandholzer H. In-home preventive comprehensive geriatric assessment (CGA) reduces mortality--a randomized controlled trial. Arch Gerontol Geriatr. 2012;55:639-644. doi: 10.1016/j.archger.2012.06.012

7. Melis RJF, Adang E, Teerenstra $S$ et al. Cost-effectiveness of a multidisciplinary intervention model for community-dwelling frail older people. J Gerontol A Biol Sci Med Sci. 2008;63:275-282. doi: 10.1093/gerona/63.3.275

8. Sahlen KG, Lofgren C, Mari Hellner B, Lindholm L. Preventive home visits to older people are cost-effective. Scand J Public Health. 2008;36:265-271. doi: 10.1177/1403494807086983

9. Stuck AE, Aronow HU, Steiner A et al. A trial of annual in-home comprehensive geriatric assessments for elderly people living in the community. N Engl J Med. 1995;333:1184-1189. doi: 10.1056/NEJM199511023331805

10. van Hout H, Jansen AP, van Marwijk H, Pronk M, Frijters DF, Nijpels G. Prevention of adverse health trajectories in a vulnerable elderly population through nurse home visits: A randomized controlled trial [ISRCTN05358495]. J Gerontol A Biol Sci Med Sci. 2010;65:734-742. doi: 10.1093/gerona/glq037

11. van Kempen JA, Robben SH, Zuidema SU, Olde Rikkert MG, Melis RJ, Schers HJ. Home visits for frail older people: a qualitative study on the needs and preferences of frail older people and their informal caregivers. Br J Gen Pract. 2012;62:554-560. doi: 10.3399/bjgp12X653606.

12. Brettschneider C, Luck T, Fleischer S, et al. Cost-utility analysis of a preventive home visit program for older adults in Germany. BMC Health Serv Res. 2015;15:141-152. doi: 10.1186/s12913-015-0817-0

13. Blom JW, Van den Hout WB, Den Elzen WPJ et al. Effectiveness and cost-effectiveness of proactive and multidisciplinary integrated care for older people with complex problems in general practice: an individual participant data meta-analysis. Age Ageing. 2018;47:705-714. doi: 10.1093/ageing/afy091

14. Liimatta H, Lampela P, Laitinen-Parkkonen P, Pitkala KH. Effects of preventive home visits on health-related quality-of-life and mortality in home-dwelling older adults. Scand J Prim Health Care. Scand J Prim Health Care. 2019;37:90-97. doi: $10.1080 / 02813432.2019 .1569372$. 
15. Liimatta H, Lampela P, Laitinen-Parkkonen P, Pitkala KH. Preventive home visits to promote the health-related quality of life of home-dwelling older people: Baseline findings and feasibility of a randomized, controlled trial. Eur Geriatr Med. 2017;8:440-445. doi: 10.1016/j.eurger.2017.06.003

16. Urbaniak GC, Plous S. Research Randomizer (Version 4.0) [Computer software]; 2013. http://www.randomizer.org/2013. Accessed August 3, 2013.

17. Sintonen $\mathrm{H}$. The 15D instrument of health-related quality of life: properties and applications. Ann Med. 2001;33:328-336. doi: 10.3109/07853890109002086

18. Kapiainen S, Väisänen A, Haula T. Terveyden- ja sosiaalihuollon yksikkökustannukset Suomessa vuonna 2011. Finnish National Institute for Health and Welfare (THL); 2014. Report No.:3/2014.

19. Bernabei R, Landi F, Onder G, Liperoti R, Gambassi G. Second and third generation assessment instruments: the birth of standardization in geriatric care. J Gerontol A Biol Sci Med Sci. 2008;63:308-313. doi: 10.1093/gerona/63.3.308

20. Lundqvist M, Alwin J, Henriksson M, Husberg M, Carlsson P, Ekdahl AW. Costeffectiveness of comprehensive geriatric assessment at an ambulatory geriatric unit based on the AGe-FIT trial. BMC Geriatr. 2018 Jan 31;18(1):32. doi: 10.1186/s12877-017-0703-1

21. Hirdes JP, Ljunggren G, Morris JN, et al. Reliability of the interRAI suite of assessment instruments: A 12-country study of an integrated health information system. BMC Health Serv Res. 2008;8:277. doi: 10.1186/1472-6963-8-277

22. Folstein MF, Folstein SE, McHugh PR. Mini-mental state. A practical method for grading the cognitive state of patients for the clinician. J Psychiatr Res. 1975;12:189-198. doi: 10.1016/0022-3956(75)90026-6

23. Guigoz Y, Lauque S, Vellas BJ. Identifying the elderly at risk for malnutrition. the mini nutritional assessment. Clin Geriatr Med. 2002;18:737-757. doi: 10.1016/S07490690(02)00059-9

24. Mahoney FI, Barthel DW. Functional evaluation: The barthel index. Md State Med J. 1965;14:61-65.

25. de Craen AJ, Heeren TJ, Gussekloo J. Accuracy of the 15-item geriatric depression scale (GDS-15) in a community sample of the oldest old. Int J Geriatr Psychiatry. 2003;18:63-66. doi: $10.1002 /$ gps.773

26. Lawton MP, Brody EM. Assessment of older people: Self-maintaining and instrumental activities of daily living. Gerontologist. 1969;9:179-186. doi: 10.1093/geront/9.3_Part_1.179

27. Russell MA, Hill KD, Blackberry I, Day LM, Dharmage SC. The reliability and predictive accuracy of the falls risk for older people in the community assessment (FROP-com) tool. Age Ageing. 2008;37:634-639. doi: 10.1093/ageing/afn129

28. Abizanda P, Navarro JL, Garcia-Tomas MI, Lopez-Jimenez E, Martinez-Sanchez E, Paterna G. Validity and usefulness of hand-held dynamometry for measuring muscle strength in community-dwelling older persons. Arch Gerontol Geriatr. 2012;54:21-27. doi: 10.1016/j.archger.2011.02.006

29. Guralnik JM, Simonsick EM, Ferrucci L, et al. A short physical performance battery assessing lower extremity function: Association with self-reported disability and prediction of mortality and nursing home admission. J Gerontol. 1994;49:M85-94.

30. Royston P. Multiple imputation of missing values. Stata J. 2004:227-41. doi: 10.1177/1536867X0400400301 
31. Metzelthin SF, van Rossum E, de Witte LP, et al. Effectiveness of interdisciplinary primary care approach to reduce disability in community dwelling frail older people: cluster randomised controlled trial. BMJ. 2013;347:f5264. doi: 10.1136/bmj.f5264

32. Bouman A, van Rossum E, Evers S, Ambergen T, Kempen G, Knipschild P. Effects on health care use and associated cost of a home visiting program for older people with poor health status: a randomized clinical trial in the Netherlands. J Gerontol A Biol Sci Med Sci. 2008;63:291-7. doi: 10.1093/gerona/63.3.291

33. Pitkala KH, Laurila JV, Strandberg TE, Kautiainen H, Sintonen H, Tilvis RS. Multicomponent geriatric intervention for elderly inpatients with delirium: effects on costs and health-related quality of life. J Gerontol A Biol Sci Med Sci. 2008;63:56-61. doi: 10.1093/gerona/63.1.56

34. Pitkala KH, Juola AL, Kautiainen H, Soini H, Finne-Soveri UH, Bell JS. Education to reduce potentially harmful medication use among residents of assisted living facilities: a randomized controlled trial. J Am Med Dir Assoc. 2014;15:892-898. doi: 10.1016/j.jamda.2014.04.002

35. Craig P, Dieppe P, Macintyre S et al. Developing and evaluating complex interventions: the new Medical Research Council guidance. BMJ. 2008;29:337. doi: 10.1136/bmj.a1655

36. Reid KF, Laussen J, Bhatia $\mathrm{K}$ et al. Translating the Lifestyle Interventions and Independence for Elders Clinical Trial to Older Adults in a Real-World Community-Based Setting. J Gerontol A Biol Sci Med Sci. 2018 Epub. doi: 10.1093/gerona/gly152

37. Greenhalgh T, Papoutsi C. Studying complexity in health services research: desperately seeking an overdue paradigm shift. BMC Med. 2018;16:95. doi: 10.1186/s12916-018-1089-4

38. Kono A, Kanaya Y, Fujita $\mathrm{T}$ et al. Effects of a preventive home visit program in ambulatory frail older people: a randomized controlled trial. J Gerontol A Biol Sci Med Sci. 2012;67:302309. doi: 10.1093/gerona/glr176

39. Alanne S, Roine RP, Räsänen $P$, Vainiola T, Sintonen H. Estimating the minimum important change in the 15D scores. Qual Life Res. 2015;24:599-606. doi: 10.1007/s11136-014-0787-4 
Table 1: Baseline Characteristics of the Participants.

\begin{tabular}{|c|c|c|c|}
\hline & $\begin{array}{l}\text { Intervention } \\
(\mathrm{N}=211)\end{array}$ & $\begin{array}{l}\text { Control } \\
(\mathrm{N}=211)\end{array}$ & $\mathrm{p}$ value \\
\hline Females, n (\%) & $138(65)$ & $136(65)$ & 0.84 \\
\hline Age, mean (SD) & $80.8(4.3)$ & $81.3(4.3)$ & 0.20 \\
\hline \multicolumn{4}{|l|}{ Marital status, n (\%) } \\
\hline Married & $110(52)$ & $105(51)$ & \\
\hline Widowed & $72(34)$ & $84(40)$ & \\
\hline Single/divorced & $28(13)$ & $19(9)$ & \\
\hline Education, years (SD), mean (SD) & $10.0(3.9)$ & $9.8(3.7)$ & 0.63 \\
\hline Charlson comorbidity index, mean (SD) & $1.3(1.3)$ & $1.4(1.5)$ & 0.61 \\
\hline HRQoL: 15D score mean (SD) & $0.823(0.110)$ & $0.824(0.111)$ & 0.87 \\
\hline \multicolumn{4}{|l|}{ Primary care, mean (SD) } \\
\hline Nurse visits & $2.31(3.70)$ & $2.57(4.11)$ & 0.52 \\
\hline General practitioner visits & $1.93(1.82)$ & $1.89(1.89)$ & 0.83 \\
\hline Other specialists' visits & $0.61(1.87)$ & $0.44(1.09)$ & 0.27 \\
\hline Primary care ward, days & $1.00(6.44)$ & $1.18(5.76)$ & 0.77 \\
\hline Day care, days & $0.47(4.92)$ & $1.42(9.43)$ & 0.21 \\
\hline \multicolumn{4}{|l|}{ Specialized medical care, mean (SD) } \\
\hline Outpatient visits & $1.13(1.86)$ & $1.12(1.95)$ & 0.98 \\
\hline Emergency department visits & $0.69(1.25)$ & $0.63(1.14)$ & 0.63 \\
\hline Hospital ward, care days & $0.99(3.18)$ & $1.16(5.03)$ & 0.70 \\
\hline
\end{tabular}

Notes: $\mathrm{n}=$ number, $\mathrm{SD}=$ standard deviation, $\mathrm{HRQOL}=$ health-related quality of life 
Table 2. Use and Costs of Health and Social Services During the 24-month Follow Up, Per Person Years (pyrs)

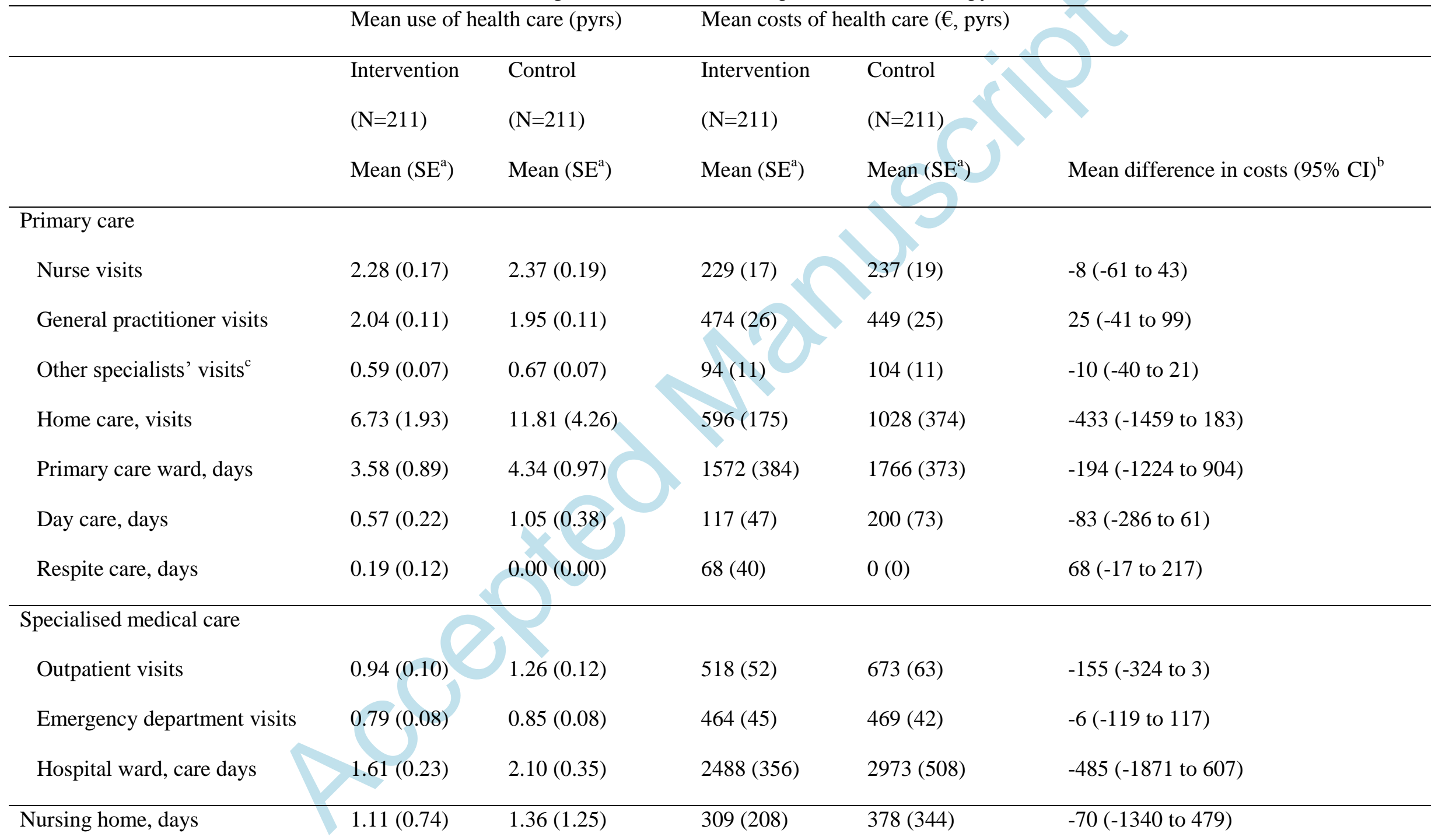


$\cdot \cdot$

${ }^{\mathrm{a}}$ Bootstrap type standard error of mean.

${ }^{\mathrm{b}}$ The $95 \%$ confidence intervals were obtained by bias-corrected bootstrapping (10,000 replications).

${ }^{\mathrm{c}}$ Other $=$ other services including physiotherapist, occupational therapist, speech therapist, nutritionist, social worker and foot-care specialist. 
Table 3. Intervention Effects on the Change in 15D Scores.

\begin{tabular}{llll}
\hline & $\begin{array}{l}\text { Intervention } \\
\text { Mean SD }\end{array}$ & $\begin{array}{l}\text { Control } \\
\text { Mean (SD) }\end{array}$ & $\begin{array}{l}\text { ifference }^{\mathrm{a}} \\
\text { Mean }(95 \% \mathrm{CI})\end{array}$ \\
\hline Baseline & $0.823(0.110)$ & $0.824(0.111)$ & \\
12 month & $0.827(0.126)$ & $0.819(0.120)$ & $0.015(0.002$ to 0.028$), \mathrm{p}=0.020$ \\
24 month & $0.825(0.116)$ & $0.816(0.120)$ & $0.009(-0.013$ to 0.031$), \mathrm{p}=0.41$ \\
\hline
\end{tabular}

${ }^{a}$ Adjusted for baseline values. 


\section{Captions}

Figure 1 Participant flow during the trial and participants included in analysis.

Figure 2 Incremental cost-effectiveness planes for costs and health-related quality-of-life outcomes of 5000 bootstrapped replicates. The percentages in the four quadrants denote the percent of the estimates that fell within each quadrant.

Table 1 Baseline Characteristics of the Participants.

Table 2 Use and Costs of Health and Social Services During the 24-month Follow Up, Per Person Years (pyrs)

Table 3 Intervention Effects on the Change in 15D Scores. 


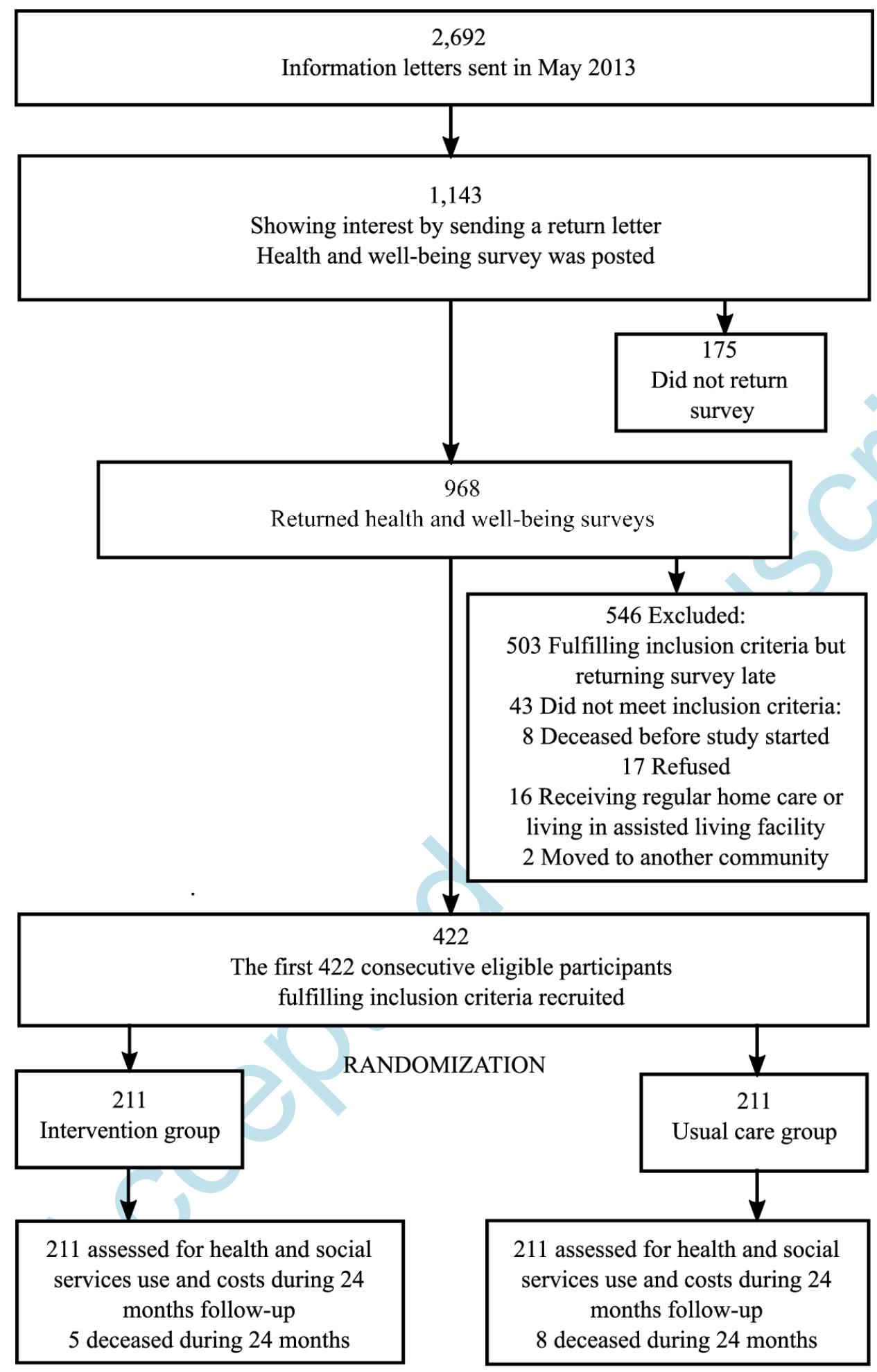

Figure 1 


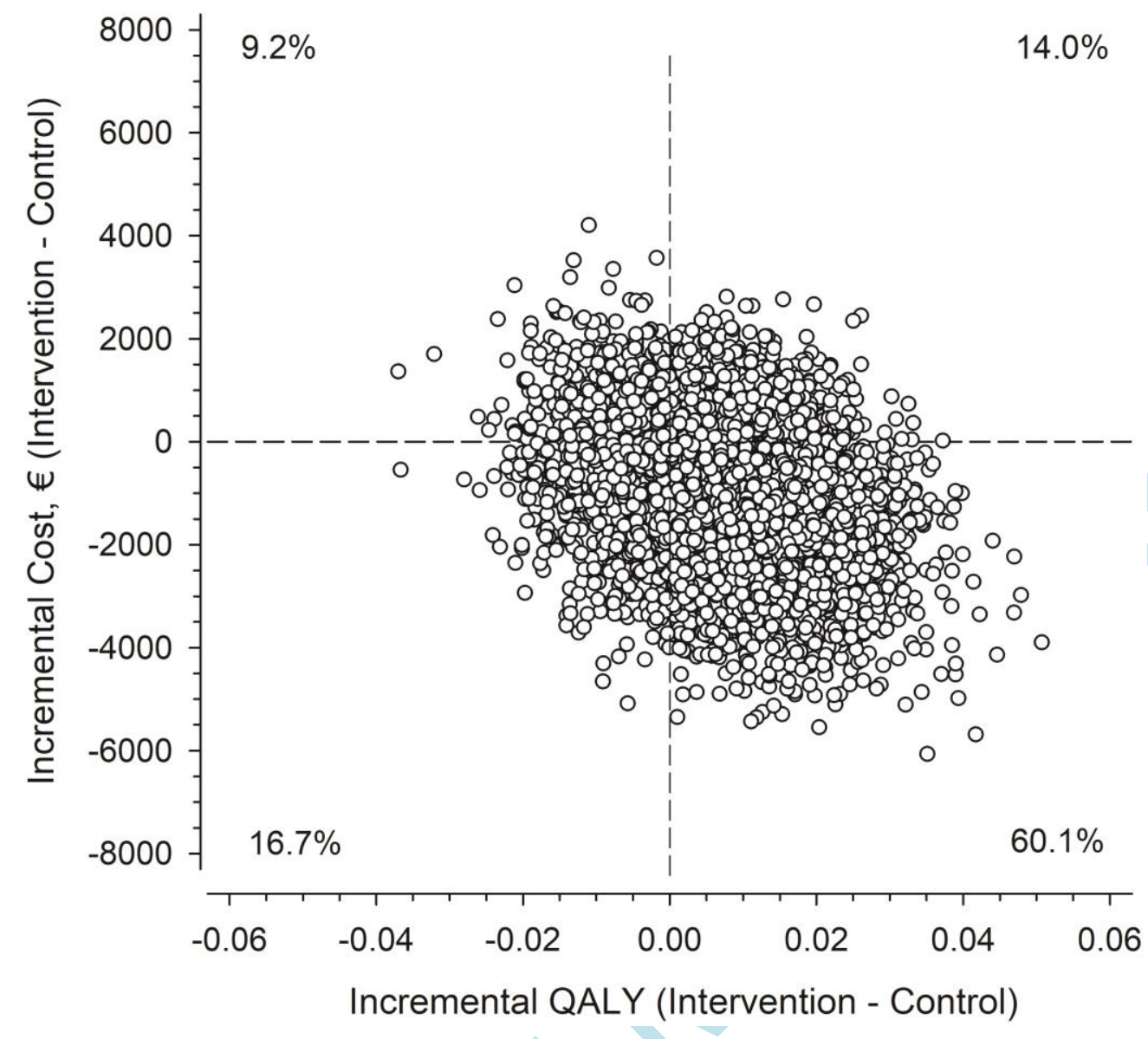

Figure 2 